\title{
CARACTERIZAC̣Āo GEOLÓGICA E PETROLÓGICA PRELIMINAR DO VULCANISMO ÁCIDO DA REGIÄO DE CAMPOS NOVOS, SANTA CATARINA
}

\author{
R.P.Philipp ${ }^{1}$, A.P.Viero ${ }^{1}$, P.C.P.Neves ${ }^{2}$, L.E.S.Robaina ${ }^{3}$, I.L.Zanette ${ }^{2}$
}

PALAVRAS-CHAVE: Bacia do Paraná, vulcanismo ácido, ignimbritos, geoquimica.

PHILIPP, R.P. et al. (1994) Caracterização geológica e petrológica preliminar do vulcanismo ácido da regiåo de Campos Novos, Santa Catarina. Bol.IG-USP, Serr.Cient., 25:17-27.

\section{RESUMO}

Trabalhos de mapeamento geológico em escala 1:50,000 foram realizados numa área de $1800 \mathrm{~km}^{2}$, localizada na regiấo centro-sul do estado de Santa Catarina, cobrindo parte das follhas de Videira c Barracăo, nos municipios de Campos Novos, Celso Ramos e Anita Garibaldi. Foram reconhecidos 5 derrames básicos sobrepostos por 6 unidades ácidas do tipo ignimbrito, perfazendo um pacote com espessura de 500 a 600 metros. Estudos petrográficos e litoquímicos de elementos maiores revelam o caráter toleitico da associaçăo e sua correlação com os basaltos baixo-titanio e ácidas tipo Palmas. Um ensaio petrogenético preliminar sugere a origem das rochas ácidas por fusão parcial de uma fonte gabróica que pode ser o correspondente intrusivo dos derrames básicos registrados na área estudada.

\section{ABSTRACT}

Geological mapping on a scale of 1:50,000 was carried out in an area of $1800 \mathrm{~km}^{2}$, located in the central part of the Videira and Barracão Sheets in the Campos Novos, Celso Ramos and Anita Garibaldi municipalities, Santa Catarina. Five basic flows followed by six acidic units, similar to ignimbrites, were recognized and comprise a 500- to 600 - m thick pile. Petrographic and major element geochemical data reveal the tholeitic character of the association and its relationship with low-titanium basalts and Palmas-type acidic rocks. Preliminary petrogenetic study suggests that the acid rocks originated by partial melting of a gabbroic parent which may be the intrusive equivalent of the basic flows of the study area.

\section{INTRODUÇĀO}

O magmatismo da Bacia do Paraná é constituído por uma espessa seqũência de rochas vulcânicas básicas e ácidas, cobrindo uma área aproximada de
$1.600 .000 \mathrm{~km}^{2} 80 \%$ dos quais $\mathrm{em}$ território brasileiro. $\mathrm{O}$ pacote vulcânico possui mais de 1500 metros de espessura na porção central da bacia, totalizando

\footnotetext{
1 Instituto de Geociencias, Universidade Federal do Rio Grande do Sul, Porto Alegre, Rio Grande do Sul, Brasil.

${ }^{2}$ Museu de Ciencias da Pontificia Universidade Católica, Porto Alegre, Rio Grande do Sul, Brasil.

${ }^{3}$ Fundação Universidade de Rio Grande, Campus Carreiro, Rio Grande, Rio Grande do Sul, Brasil.
} 
um volume próximo a $1.300 .000 \mathrm{~km}^{3}$ (Renne et al., 1992).

A região em estudo, situada na porção centro-sul do estado de Santa Catarina, é composta por uma associação de rochas vulcânicas, de caráter predominantemente ácido, correspondendo à Formação Serra Geral. As unidades vulcânicas abordadas representam uma fração do evento magmático anorogênico vinculado à etapa final do ciclo tectônico gerador da Bacia do Paraná. A área em foco faz parte das Folhas Barracão e Videira (1:50.000), tendo como limites geográficos os paralelos $27^{\circ} 20^{\circ} 00^{\prime \prime} \mathrm{e}$ $27^{\circ} 41^{\circ} 30^{\circ} \mathrm{S}$ e os meridianos $51^{\circ} 00^{\circ} 00^{\prime \prime}$ e $51^{\circ} 25^{\prime} 00^{\prime \prime}$ W (Fig. 1).

Os primeiros estudos sobre o vulcanismo na Bacia do Paraná foram realizados principalmente na região sudeste da bacia, enfatizando os aspectos geológicos, petrográficos e geocronológicos (Baker, 1923; Melfi, 1967; Amaral et al., 1966; Ruegg \& Amaral, 1976; Rocha Campos et al., 1988). Estes trabalhos caracterizam o pacote vulcânico como sendo composto por vários derrames basálticos de idades Juro-Cretáceas. Estudos geocronológicos mais atualizados de ${ }^{40} \mathrm{Ar} / 39 \mathrm{Ar}$, definem o magmatismo da Bacia do Paraná como um episódio de curta duracão e de idade cretácea (Renne et al., 1992; Turner et al., 1994).

Publicações mais recentes demonstram a ocorrência de composições ácidas posicionadas nas porções de topo da seqüência vulcânica (Sartori et al., 1982; Sartori \& Filho, 1983; Bellieni et al., 1984, 1986; Mantovani et al., 1985; Roisenberg, 1989; Piccirillo et al., 1988a, b, 1990).

Levantamentos aerofotogramétricos demonstram a existência de lineamentos tectônicos regionais, de direção $\mathrm{N} 20-30 \mathrm{E}$ e N50-60E. Em campo, estas feições estruturais estão marcadas por fraturas verticais que cortam a sequêencia vulcânica. Subordinadamente, lineamentos de direção NW estão marcados em campo por
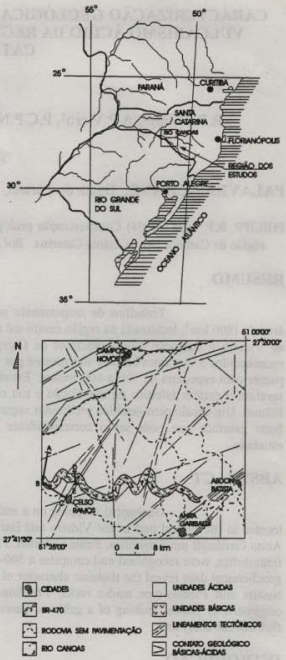

Figura 1 - Mapa de localização e gcológico da região estudada.

fraturas preenchidas por diques de diabásio.

O principal objetivo deste trabalho é o reconhecimento geológico e petrográfico das unidades efusivas, com enfoque subordinado aos aspectos litoquímicos e genéticos. Os dados apresentados resultaram do mapeamento geológico sistemáti- 
co, desenvolvido pelos autores, cobrindo uma área de $1800 \mathrm{~km}^{2}$ nos municipios de Campos Novos, Celso Ramos e Anita Garibaldi.

\section{ASPECTOS GEOLÓGICOS}

A região estudada compreende um pacote vulcânico de 500 a 600 metros de espessura, onde foram identificadas 5 unidades básicas sobrepostas por 6 unidades ácidas, individualizadas a partir de perfis geológicos e do estudo de testemunho de sondagens cedidos pela Eletrosul. Os critérios utilizados na delimitação das unidades foram a ocorrên- cia de zonas amígdalo-vesiculares, zonas vitreas e horizontes de brechas de fluxo.

Diques de diabásio de direção NW, com espessuras métricas, são registrados cortando a sequência ácida, indicando a recorrência do magmatismo de composição básica.

O relevo da região mapeada tem como elemento morfológico principal um extenso platô de rochas ácidas que perfaz aproximadamente $95 \%$ da área. A dissecação de zonas intensamente fraturadas gerou vales estreitos e profundos, onde o nível da erosão ao longo do Rio Canoas alcança as rochas básicas (Fig. 2).
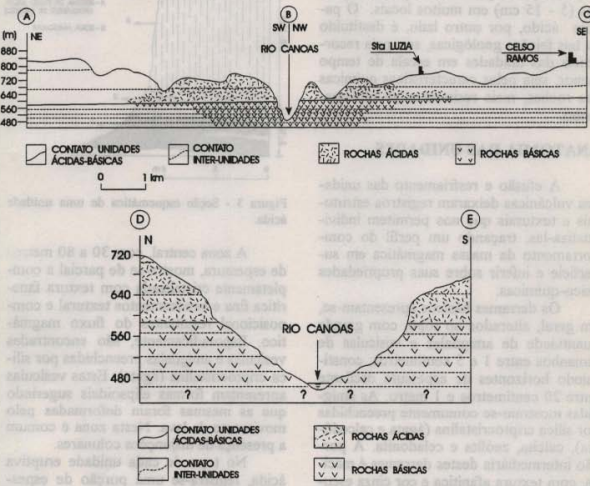

$1 \mathrm{~km}$

Figura 2 - Perfis geológicos ao longo do Rio Canoas. Localização dos perfis na Figura 1. 
A disposição sub-horizontal e a ausência de deslocamentos tectônicos verticais significativos de blocos rochosos, permitiu o estabelecimento de cotas definidas para as unidades básicas e ácidas. Os derrames básicos situam-se em cotas inferiores a 580 metros, exibindo espessuras entre 15 e 40 metros. Nos niveis superiores a 580 metros encontram-se as unidades ácidas, cuja espessura varia de 60 a 120 metros, atingindo altitudes de até 1050 metros próximas aos municípios de Anita Garibaldi e Abdon Batista.

A extrusão dos derrames básicos transcorreu com periodos de intermitência significativos, os quais estão marcados pe la presença de paleossolos pouco espessos $(5$ - $15 \mathrm{~cm})$ em muitos locais. 0 pacote ácido, por outro lado, é destituído de tais feiçốes geológicas, seja pela recorrência das unidades em escala de tempo menor, seja pelas características químicas das rochas, mais resistentes ao intemperismo.

\section{ANATOMIA DAS UNIDADES}

A efusão e resfriamento das unidades vulcânicas deixaram registros estruturais e texturais que nos permitem individualizá-las, traçando um perfil do comportamento da massa magmática em superficie e inferir sobre suas propriedades físico-químicas.

Os derrames básicos apresentam-se, em geral, alterados no topo, com grande quantidade de amigdalas e vesículas de tamanhos entre 1 e 5 centimetros, constituindo horizontes de espessura oscilante entre 20 centímetros e 1 metro. As amígdalas mostram-se comumente preenchidas por sílica criptocristalina (ágata e calcedônia), calcita, zeólita e celadonita. A porção intermediária destes derrames é maciça, com textura afanítica e cor cinza escura. $\mathrm{Na}$ base são encontradas amígdalas em pequena quantidade, por vezes, fortemente alongadas.

A anatomia geral das unidades áci- das (Fig. 3) é caracterizada, nas porções basais, por uma zona vitrea com fraturas de contração horizontais e espessura entre 2,0 e 10,0 metros. Em decorrência da sua forte instabilidade, o material amorfo sofre intensa alteração intempérica e transforma-se numa massa argilosa que é transportada pela água subsuperficial propiciando o aparecimento de cavernas em muitos locais.

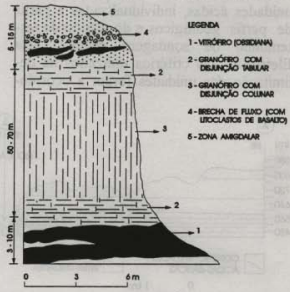

Figura 3 - Seção esquemática de uma unidade ácida.

A zona central, com 30 a 80 metro: de espessura, mostra-se de parcial a completamente cristalizada com textura fanerítica fina e bandeamentos textural e composicional resultantes do fluxo magmático. Esporadicamente, são encontradas vesículas e amigdalas preenchidas por silica criptocristalina (ágata). Estas vesículas apresentam formas elipsoidais sugerindo que as mesmas foram deformadas pelo movimento da lava. Nesta zona é comum a presença de disjunçōes colunares.

No topo de cada unidade eruptiva ácida, registra-se uma porção de espessura heterogênea $(3$ a $10 \mathrm{~m})$ rica em amigdalas e vesículas e com abundante material não cristalino. As cavidades exibem diâmetros variados (5 a $20 \mathrm{~cm}$ ) e 
preenchimento por silica, originando as expressivas ocorrências de ágata da região. Por vezes, ocorrem juntas de contração horizontais e brechas, estas produzidas pela incorporação de blocos congelados do topo da unidade, fragmentado pelo movimento da massa ainda fluída da zona central. A este processo denominase autobrechação.

Brechas de origem tectônica são encontradas ao longo de toda a região como zonas verticais de espessura centimétrica a métrica, cortando mais de uma unidade eruptiva. Caracterizam-se pela presença de fragmentos angulosos cimentados por quartzo e calcita.

\section{ASPECTOS PETROGRÁFICOS}

\section{Rochas Básicas}

As unidades básicas possuem cor cinza escuro e textura afanitica. Em geral pessos níveis de solos argilosos de coloração avermelhada.

Ao microscópio, exibem um caráter porfirítico com raros fenocristais de plagioclásio e olivina pseudomorfisada, demonstrando, por vezes, um fraco alinhamento dos cristais prismáticos da matriz. Nas porções centrais dos derrames 0 arranjo é ofitico a subofitico com tamanho de grão inferior a $0,15 \mathrm{~mm}$, enquanto que nas zonas de base e de topo é freqüente a textura intersertal.

Os minerais essenciais são representados por plagioclásio e clinopiroxênio, com opacos, olivina e apatita como acessórios. A assembléia de alteração é formada por argilo-minerais, opacos e clorita, enquanto as amigdalas estão preenchidas por zeólitas, quartzo, calcita e calcedônia (Tabela 1).

O plagioclásio apresenta forma pris são da ordem de 4,0 milimetros, mostram

Tabela 1. Composição modal de rochas vulcânicas da região de Campos Novos, SC.

$\begin{array}{lccc}\text { Amostra } & \text { Plagiocl. } & \text { Clinopx. } & \text { Opacos } \\ \text { CN-1 } & 20 & 12 & 5 \\ \text { CN-18 } & 25 & 15 & 4 \\ \text { CN-21 } & 20 & 10 & 5 \\ \text { CN-23 } & 30 & 16 & 7 \\ \text { CN-32 } & 12 & 9 & 3 \\ \text { CN-242 } & 7 & 3 & 5 \\ \text { CN-60B } & 20 & 18 & 9 \\ \text { CN-216 } & 20 & 12 & 3 \\ \text { CN-238 } & 15 & 8 & 2 \\ \text { CN-469 } & 21 & 12 & 5 \\ \text { CN-489 } & 22 & 10 & 3 \\ \text { CN-240 } & 25 & 10 & 3 \\ \text { CN-63 } & 45 & 45 & 7 \\ \text { CN-85 } & 50 & 44 & 4 \\ \text { CN-265 } & 55 & 35 & 8 \\ \text { CN-395 } & 50 & 41 & 8\end{array}$

* = Dacitos e riolitos; + = Basaltos

mática e compreende a fase mais abundante, ocorrendo na matriz e como fenocristais. Os fenocristais, cujas dimensões estão bastante alteradas, constituindo es-

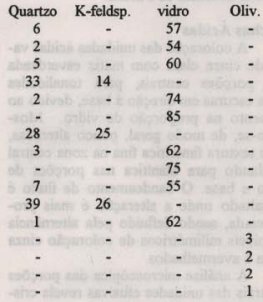

forte zoneamento e feições de fusão parcial, como textura sieve. Na matriz os indivíduos possuem hábito ripiforme e mosram incipiente alteração para argilo-mi- 
nerais e raramente para carbonatos.

O clinopiroxênio é encontrado na matriz como cristais límpidos, subédricos de formas arredondadas e com dimensões da ordem de 0,2 milimetros.

Escassos fenocristais de olivina, com tamanho ao redor de 3,0 milimetros, estão pseudomorfisados para argilo-minerais, serpentina e óxidos metálicos. As formas são arredondadas, ocorrendo nítidas feiçōes de reação com o liquido magmático (bordos corroídos).

Os minerais opacos são os principais componentes acessórios, ocorrendo como fases magmática e de alteração. No primeiro caso possuem formas euédricas com seções equidimensionais, sugerindo tratar-se de magnetita. As fases de alteração mostram formas irregulares e resultam da instabilização da olivina e do clinopiroxênio.

As rochas basálticas de Campos Novos possuem fortes similaridades petrográficas com as demais vulcânicas básicas da Bacia do Paraná.

\section{Rochas Ácidas}

A coloração das unidades ácidas varia de cinza clara com matiz esverdeada nas porções centrais, para tonalidades mais escuras em direção à base, devido ao aumento na proporção de vidro. Mostram-se, de modo geral, pouco alteradas, com textura fanerítica fina na zona central gradando para afanítica nas porções de topo e base. O bandeamento de fluxo é ressaltado onde a alteração é mais pronunciada, sendo definido pela alternância de níveis milimétricos de coloração cinza clara e avermelhados.

A análise microscópica das porções centrais das unidades efusivas revela cristais ripiformes de plagioclásio e clinopiroxênio imersos em uma massa granofirica de quartzo e feldspato alcalino. Nas zonas de topo e de base a rocha adquire um caráter hialocristalino.

As fases essenciais são compostas por plagioclásio, clinopiroxênio e quart- zo-feldspato alcalino intercrescidos. Estes componentes são substituídos por vidro nas zonas de topo e base (Tabela 1).

O plagioclásio é o mineral mais abundante, aparecendo como cristais limpidos, ripiformes e aciculares com terminações em cauda de andorinha, tendo dimensões variáveis entre 0,2 e 0,5 milimetros. Formas esqueléticas são observadas com frequeência, salientando o rápido crescimento dos cristais.

O clinopiroxênio apresenta hábito prismático fortemente alongado, com tamanhos de 0,1 a 0,4 milimetros e alteração muito incipiente.

Envolvendo os cristais de plagioclásio e clinopiroxênio ocorre, nas porções centrais das unidades, uma massa eutética de quartzo e feldspato alcalino esferuliti$\cos$, provavelmente resultante da cristalização de vidro.

Os minerais opacos são representados, provavelmente, por magnetita, caracterizando-se por formas euédricas e esponjosas, correspondentes a geraçōes primária e secundária, respectivamente.

A apatita é um acessório comum, possuindo hábitos aciculares e aspecto incolor

\section{LITOQuímICA}

Foram selecionadas 11 amostras representativas das unidades básicas e ácidas para os estudos litogeoquímicos, com objetivos de caracterizar e fazer algumas consideraçōes quanto aos aspectos petrogenéticos. As análises de elementos maiores foram feitas por Fluorescência de raios-x nos laboratórios da Geosol (Tabela 2).

Os resultados mostram a ocorrência de duas populações quimicamente distintas, uma representada por basaltos, com teores de sílica entre 50 e $54 \%$, e a outra por riólitos e dacitos, com sílica variando de 65 a $68 \%$ (Figs. 4 e 5 ). As rochas basálticas contém $\mathrm{TiO}_{2}$ abaixo de $1,60 \%$ e mostram empobrecimento em álcalis, o 
Tabela 2. Composição química de elementos maiores das rochas vulcânicas básicas e ácidas da região de Campos Novos, SC.

\begin{tabular}{|c|c|c|c|c|c|c|c|c|c|c|c|}
\hline \multicolumn{4}{|c|}{ BASALTOS } & \multicolumn{6}{|c|}{ DACITOS E RIOLTIOS } & \\
\hline & $\mathrm{CN}-8$ & $\mathrm{CN}-26$ & $\mathrm{CN}-39$ & $\mathrm{CN}-48$ & $\mathrm{CN}-60$ & $\mathrm{CN}-24$ & $\mathrm{CN}-24$ & $\mathrm{CN}-21$ & $\mathrm{CN}-3$ & $\mathrm{CN}-23$ & $\mathrm{CN}-46$ \\
\hline $\mathrm{iO}_{2}$ & 50.7 & 53.2 & 51.7 & 66.9 & 67.2 & 65.6 & 66.9 & 66.1 & 68.0 & 67.4 & 66.5 \\
\hline & 1.5 & 1.6 & 1.4 & 1.0 & 0.9 & 1.1 & 1.1 & 1.0 & 0.9 & 1.0 & 1.1 \\
\hline $\mathrm{H}_{2} \mathrm{O}$ & 14.0 & 13.5 & 14.0 & 12.6 & 12.7 & 12.3 & 12.4 & 12.6 & 12.3 & 12.2 & 12.9 \\
\hline $\mathrm{e}_{2} \mathrm{O}_{3} \mathrm{t}$ & 14.4 & 13.9 & 13.8 & 6.5 & 6.5 & 6.5 & 6.9 & 7.2 & 6.8 & 7.2 & 6.8 \\
\hline & 4.5 & 4.0 & 4. & 0.9 & 4 & 0.4 & 0.3 & 1.2 & 0.4 & 0.3 & 0.5 \\
\hline & 10.4 & 8.6 & 9.8 & 2.6 & 2.4 & 3.8 & 2.6 & 2.9 & 2.8 & 2.2 & 2.6 \\
\hline & 2.3 & 2.5 & 2.0 & 3.0 & 3.3 & 3.7 & 3.2 & 3.2 & 2.9 & 2.6 & 3.7 \\
\hline $\mathrm{K}_{2}$ & 0.5 & 1.5 & 1.1 & 4.2 & 4.0 & 2.7 & 4.5 & 3.9 & 4.4 & 4.8 & 3.9 \\
\hline & 0.6 & 0.4 & 0.4 & 1.3 & 1.8 & 3.1 & 1.0 & 1.3 & 0.8 & 1.3 & 1.0 \\
\hline
\end{tabular}
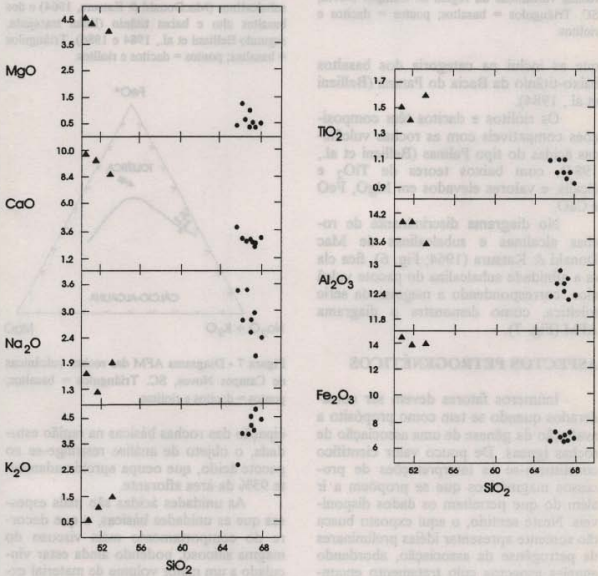

Figura 4 - Diagramas de variação quimica das rochas vulcânicas de Campos Novos, SC, tendo $\mathrm{SiO}_{2}$ como indices de diferenciação. Triângulos $=$ basaltos; pontos $=$ dacitos $\mathrm{e}$ riolitos. 


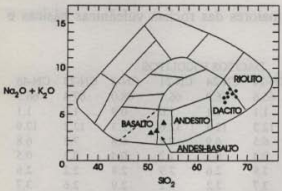

Figura 5 - Diagrama de classificaçáo $\mathrm{SiO}_{2} \times$ $\mathrm{Na}_{2} \mathrm{O}+\mathrm{K}_{2} \mathrm{O}$, segundo $\mathrm{Cox}$ et al. (1979), das rochas vulcânicas da região de Campos Novos, SC. Triângulos $=$ basaltos; pontos $=$ dacitos $\mathrm{e}$ riolitos.

que as inclui na categoria dos basaltos baixo-titânio da Bacia do Paraná (Bellieni et al., 1984).

Os riólitos e dacitos têm composiç̃̃es compatíveis com as rochas vulcânicas ácidas do tipo Palmas (Bellieni et al., 1984), com baixos teores de $\mathrm{TiO}_{2}$ e álcalis, e valores elevados em $\mathrm{MgO}, \mathrm{FeO}$ e $\mathrm{CaO}$.

No diagrama discriminante de rochas alcalinas e subalcalinas de Mac Donald \& Katsura (1964; Fig. 6), fica cla ra a afinidade subalcalina do pacote vulcâ nico, correspondendo a magmas da série toleítica, como demonstra o diagrama AFM (Fig. 7).

\section{ASPECTOS PETROGENÉTICOS}

Inúmeros fatores devem ser considerados quando se tem como propósito a avaliação da gênese de uma associação de rochas ígneas. De pouco valor científico constituem-se as interpretações de processos magmáticos que se propõem a ir além do que permitem os dados disponiveis. Neste sentido, o aqui exposto busca tão somente apresentar idéias preliminares da petrogênse da associação, abordando aqueles aspectos cujo tratamento encontra respaldo satisfatório nos dados obtidos. Em virtude da inexpressiva parti-

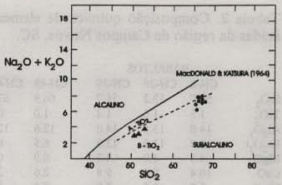

Figura 6 - Diagrama $\mathrm{Na}_{2} \mathrm{O}+\mathrm{K}_{2} \mathrm{O}$ contra $\mathrm{SiO}_{2}$ das rochas vulcanicas de Campos Novos, SC, discriminando os campos de basaltos alcalinos $\mathrm{e}$ subalcalinos (MacDonald \& Katsura, 1964) e dos basaltos alto e baixo titânio (linha tracejada, segundo Bellieni et al,, 1984 e 1986). Triângulos = basaltos; pontos = dacitos e riolitos.

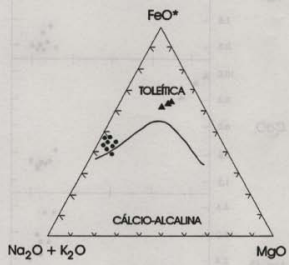

Figura 7 - Diagrama AFM das rochas vulcânicas de Campos Novos, SC. Triângulos = basaltos; pontos $=$ dacitos e riolitos.

cipação das rochas básicas na região estudada, o objeto de análise restringe-se ao pacote ácido, que ocupa aproximadamente $95 \%$ da área aflorante.

As unidades ácidas são mais espessas que as unidades básicas, o que decorre do comportamento mais viscoso do magma silicoso, podendo ainda estar vinculado a um maior volume de material expelido em cada evento eruptivo. A anatomia das unidades ácidas tem forte influên- 
cia da espessura, ocorrendo zonas vitreas na base e no topo e uma porção central faneritica fina. Nos niveis vítreos são observadas texturas tipicas de crescimento rápido, como cristais aciculares de plagioclásio e piroxênio com terminações em cauda de andorinha. $\mathrm{Na}$ zona central, por outro lado, a retenção de calor propicia a cristalizaçăo mais lenta, resultando no aumento do tamanho de grão com formas prismáticas e intercrescimento granofirico.

A presença frequiente de um bandeamento milimétrico regular e contínuo, por vezes dobrado, aponta para o fluxo piroclástico como o mecanismo de enupção. Cabe ressaltar, entretanto, que nã̃o foram registradas feições texturais diagnósticas, as quais provavelmente estão obliteradas face ao elevado grau de soldamento dos fragmentos, conforme sugerido por Roisenberg (1989) para os ignimbritos do nordeste do Rio Grande do Sul. $\mathbf{O}$ intenso soldamento resulta da alta temperatura do magma quando da efusão, a qual foi superior à temperatura do "liquidus", como indicado pelo caráter afirico das rochas.

A provável existência de relações genéticas entre as unidades básicas e ácidas poderia ser atribuída ao fracionamento de minerais a partir de um liquido inicial de composição igual ou similar a dos basaltos, com os dacitos e riolitos representando o resíduo de cristalização. Quando, entretanto, uma associação de rochas ígneas é gerada por cristalização fracionada, espera-se que a seqüência contenha todos os intervalos composicionais entre os termos extremos. Não é, contudo, o que se registra na área estudada, onde há uma bimodalidade química.

A fusão parcial de uma fonte gabróica de quimismo similar ao dos basaltos da regiâo estudada constitui uma hipótese petrogenética alternativa para os dacitos e riolitos. Esta hipótese foi apresentada por Bellieni et al. (1984) para explicar a gênese do pacote ácido da Bacia do Paraná, em âmbito global. $\mathbf{O}$ balanço de massas, utilizando elementos maiores, forneceu resultados consistentes com $16 \%$ de fusão parcial de gabro, restando um residuo com $48 \%$ de plagioclásio, $42 \%$ de augita e $10 \%$ de magnetita. A soma do quadrado dos residuos é de 0,35 . Como representante da composição da rocha-fonte utilizou-se a amostra $\mathrm{CN}-85$ (basalto), enquanto que à amostra $\mathrm{CN}-32$ atribuiu-se a composição da fusão (riodacito).

A boa concordância dos dados químicos com o processo de fusão parcial não encontra respaldo nas informações isotópicas. Estudos de Cordani et al. (1988) registram valores de $\left({ }^{87} \mathrm{Sr} / 86 \mathrm{Sr}\right)_{0}$ variando entre 0,704 e 0,712 nos basaltos e 0,718 e 0,728 nos riolitos e riodacitos do Sul da Bacia do Paraná. Nota-se aqui, todavia, a forte dispersão dos valores, presente nos dois tipos de rocha, o que pode indicar heterogeneidade na fonte ou processos de assimilação crustal em graus muito diversos. Parece pouco convincente a primeira hipótese, principalmente no que se refere aos basaltos, haja vista que, mesmo os basaltos alcalinos, que representam fusões de manto enriquecido (metassomatisado), e que, portanto, exibiriam as maiores razões iniciais, não possuem valores tão elevados quanto 0,712 na ausência de assimilação de crosta.

A discrepância isotópica entre basaltos e riodacitos-riolitos não significa, portanto, necessariamente a falta de correlação genética entre ambos. A assimilação crustal, claramente verificada nos primeiros, pode ter atuado na evolução dos últimos, de modo a alterar sua assinatura isotópica original. Não deve, contudo, ter influenciado significativamente na composição dos elementos maiores, que mostram ajuste satisfatório no modelamento de fusão parcial. Este resultado é obtido desde que a crosta assimilada e o magma assimilante apresentem composiçōes similares em elementos maiores e distintas isotopicamente, o que se mostra coerente 
quando um magma riolitico assimila crosta granítica.

\section{REFERÊNCIAS BIBLIOGRÁFICAS}

ALMEIDA, F.F.M. (1983) Sintese sobre a tectônica da Bacia do Paraná. In: SIMPÓSIO BRASILEIRO DE GEOLOGIA, 4., São Paulo, 1983. Atas. São Paulo.

AMARAL, G; CORDANI, U.G; KAWASHITA, $\mathrm{K}$; REYNOLDS, J.H. (1966) Potassium-Argon dates of basaltic rocks from southern Brazil. Geochemical et Cosmochemical Acta, v. 30, n.2, p.159-189.

BAKER, C.L. (1923) The lava field of the Paraná Basin, South America. Journal of Geology, v. 31, n.2, p.66-79.

BELLIENI, G.; COMIN-CHIARAMONTI, P.; MARQUES, L.M.; MELFI, A.J.; PICCIRILLO, E.M.; NARDY, A.J.R; ROISENBERG, A. (1984) High- and low- $\mathrm{TiO}_{2}$ flood basalts from Paraná Plateau (Brazil): petrology and geochemical aspects bearing on their mantle origin. Neues Jahrbuch Mineralogie Abhandlungen, v.150, p.273306.

BELLIENI, G.; COMIN-CHIARAMONTI, P; MARQUES, L.M; MELFI, A.J.; NARDY, A.J.R.; PAPATRECHAS, C; PICCIRILLO, E.M.; ROISENBERG, A.; STOLFA, D. (1986) Petrogenetic aspects of acid and basaltic lavas from Paraná Plateau (Brazil): geological, mineralogical and petrochemical relationships. Journal of Petrology, v.31, n.2, p.915-944.

CORDANI, U.G.; CIVETTA, L.; MANTOVANI, M.S.M.; PETRINI, R; KAWASHITA, K; HAWKESWORTH, C.J.; TAYLOR, P.; LONGINELLI, A.; CAVAZZINI, G.; PICCIRILLO, E.M. (1988) Isotope geochemistry of flood volcanics from the Paraná Basin (Brazil). In: PICCIRILLO, E.M; MELFI, A.J. (eds.) The mesozoic flood volcanism of the $\mathrm{Pa}$ - raná Basin: petrogenetic and geophysical aspects. Sã̃o Paulo, Instituto Astronômico e Geofisico. p.157-178.

COX, K.G.; BELL, J.D.; PANKHURST, R.J. (1979) The interpretation of igneous rocks. London, Allen \& Unwin. 450p.

MacDONALD, G.A; KATSURA, T. (1964) Chemical composition of Hawaiin lavas. Journal of Petrology, v.5, n.1, p.82-133.

MANTOVANI, M.S.M; CORDANI, U.G.; ROISENBERG, A. (1985) Geoquímica isotópica em vulcânicas ácidas da Bacia do Paraná, e implicações genéticas associadas. Revista Brasileira de Geociências, v. 15, n.1, p.61-65.

MELFI, A.J. (1967) Potassium-argon ages of core samples of basaltic rock: from southern Brazil. Geochimica et Cosmochimica Acta, v.31, n.6, p. 1079-1089.

PICCIRILLO, E.M: COMIN-CHIARAMONTI, P.; MELFI, A.J.; STOLFA, D.; BELLIENI, G.; MARQUES, L.S.; GIARETTA, A.; NARDY, A.J.R.; PINESE, J.P.P.; RAPOSO, M.I.B; ROISENBERG, A. (1988a) Petrochemistry of continental flood basaltrhyolite suites and related intrusives from the Paraná Basin (Brazil). In: PICCIRILLO, E.M.; MELFI, A.J. (eds.) The mesozoic flood volcanism of the Paraná Basin: petrogenetic and geophysical aspects. São Paulo, Instituto Astronômico e Geofísico. p. 107-156.

PICCIRILLO, E.M.; COMIN-CHIARAMONTI, P.; BELLIENI, G.; CIVETTA, L.; MARQUES, L.S.; MELFI, A.J.; PETRINI, R.; RAPOSO, M.I.B.; STOLFA, D. (1988b) Petrogenetic aspects of continental flood basaltrhyolite suites from the Paraná Basin (Brazil). In: PICCIRILLO, E.M.; MELFI, A.J. (eds.) The mesozoic flood volcanism of the Paraná Basin: petrogenetic and geophysical aspects. p.179-206. 
PICCIRILLO, E.M; BELLIENI, G.; CAVAZZINI, P.; COMIN-CHIARAMONTI, P.; PETRINI, R; MELFI, A.J.; PINESE, J.P.P.; ZANTADESCHI, P.; De MIN, A. (1990) Lower Cretaceous tholeiitic dyke swarms from the Ponta Grossa Arch (southeast Brazil): petrology, $\mathrm{Sr}-\mathrm{Nd}$ isotopes and genetic relationships with the Parana flood volcanics. Chemical Geology, v. 89, n. 1, p. $19-48$.

RENNE, P.R.; ERNESTO, M.; PACCA, I.G.; COE, R.S.; GLEN, J.M; PREVOT, M.; PERRIN, M. (1992) The age of Paraná Flood Volcanism, Rifting of Gondwanaland, and the Jurassic-Cretaceous Boundary. Science, v. 258, n. 5084, p. $975-979$.

ROCHA CAMPOS, A.C.; CORDANI, U.G.; KAWASHITA, K.; SONOKI, H.M.; SONOKI, I.K. (1988) Age of the Paraná flood volcanism. In: PICCIRILLO, E.M.; MELFI, A.J. (eds.) The mesozoic flood volcanism of the $\mathbf{P a}$ raná Basin: petrogenetic and geophysical aspects. São Paulo, Instituto Astronômico e Geofísico. p.25-45.

ROISENBERG, A. (1989) Petrologia e geoquímica do vulcanismo ácido mesozóico da Província Meridional da Bacia do Paraná. Porto Alegre, 285p. (Tese - Doutorado) Instituto de Geociências, Universidade Federal do Rio Grande do Sul.

RUEGG, N.R; AMARAL, G. (1976) Variação regional da composição química das rochas basálticas da Bacia do Paraná. Boletim IG-USP, n.7, p.131147.

SARTORI, P.L.P; BORTOLOTTO, O.J.; KAWASHITA, K. (1982) Os principais tipos de rochas vulcânicas da Bacia do Paraná no planalto de Santa Catarina. Ciência e Natura, v.4, p.7184.

SARTORI, P.L.P.; FILHO, C.L.M. (1983) Petrografia das rochas ácidas da Formação Serra Geral na região do Rio Paranapanema, São Paulo. Ciência e Natura, v.5, p.19-23.

TURNER, S.; REGELOUS, M.; KELLEY, S.; HAWKESWORTH, C.; MANTOVANI, M. (1994) Magmatism and continental break-up in the South Atlantic, high precision (40)Ar(39)Ar geochronology. Earth and Planetary Science Letters, v.121, n. 3-4, p.333-348.

R.P.Philipp - Instituto de Geociências - UFRGS, Caixa Postal 15.001, CEP 91501-970, Porto Alegre, RS, Brasil. 